\title{
P-22 USING OF NEW SEISMIC INTERPRETATION FOR EXPLORATION OF CARBONATE TRAPS IN EXTERNAL ALBANIDES
}

VILSON BARE, ILIA FILI, ALEKS LEKA and AJET MEZINI

Tirana University, Oil and Gas institute, Fier, Albania

\begin{abstract}
Introduction
The area under studying is situated in the Southwestern part of Albania. A number of oilfields within the orogene have been found over the platform. There are analysed a lot of different cases of trapping in carbonate structures. Application of the SeisWork2D is a powerful interpretative tool that gives us new insight into the subsurface. Subtle details that would be hidden on paper section are revealed on the screen, thanks to color, high-resolution graphics and a wide variety of display options.
\end{abstract}

Gathered and analysed data consist of exploration and development wells, seismic lines, logs, well testing, geochemical and petrophysical analyses. Sometypes of the traps are demonstrated practically and are prescribed in conformity with incontestable the facts data. The paper intent to explain main geological factors that influenced in trap formation in carbonate reservoirs and the characteristics of seismic facies on carbonate. The experience shows that it is difficult to explore the traps in a complicated geological framework, where a complex of the geological phenomena's are interfered

\section{Factors that determine trap formations in thrust belts.}

Thrust belts are structurally complex with attendant seismic imaging problems

Exploration experience in Albania, show that, Oil bearing problems in carbonate structures can be clarifies, through trapping. Trap formation on carbonate reservoirs is strictly connected with deformation history, erosion, unconformity and other geological phenomenon. Folding is the most important factor on trap formation. Carbonate folding was intensive in ExternalAlbanides Fig. 1

In anticline belts are formed structural traps with a large massive volume of carbonate depositions.

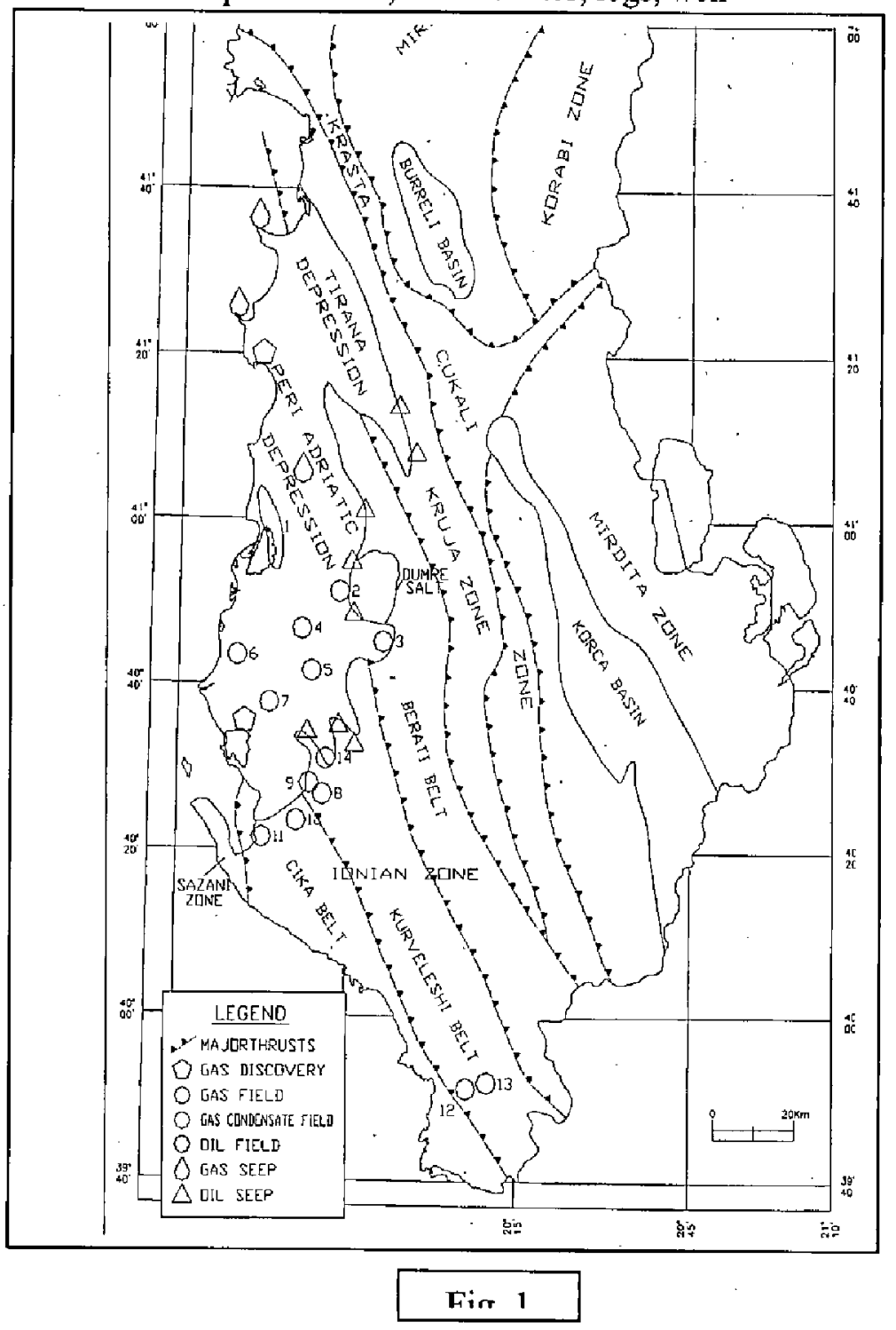


Massive structural traps formed beginning from Late Oligocene to Lower Miocene. It's main phase of the trap formation.

Later the new geological conditions, leads to the reformation of the previous traps and creation of the

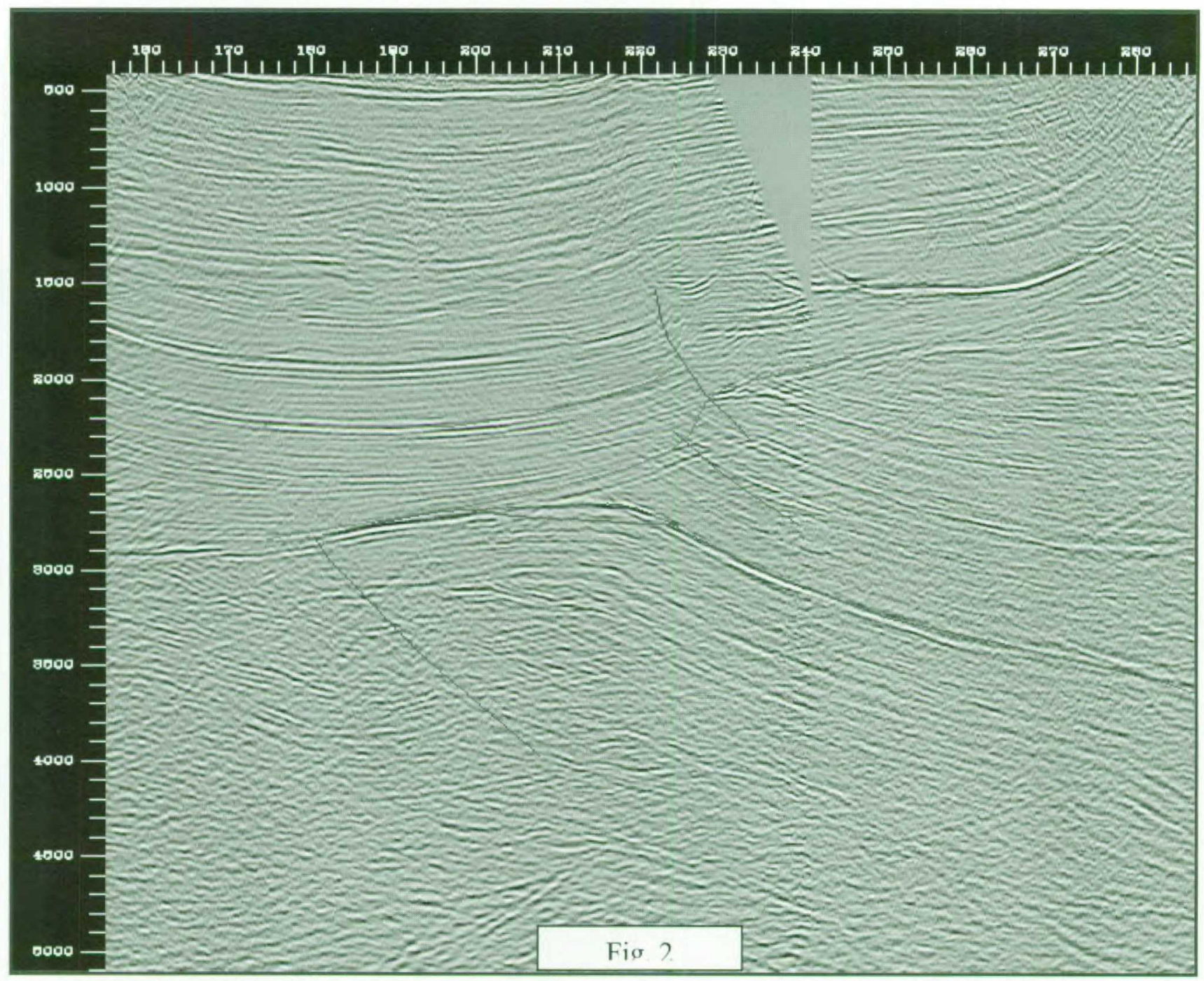

other types of traps. These new geological conditions are: -Seal of the flysch deposits and a part of carbonate section were eroded.

-Changing of the structural plane, caused re-migration.

-Hydrodynamic situation affected too or more screening opportunities:

-Transgressive laying of the Neogene deposits-over some carbonate structures, influenced on stratigraphic trap formation, (seismic line Fig. 2).

-Compressive regime and further over thrusting during Neogene's, of the carbonate core anticlines, led to fault-limited blocks.

Trapping history on carbonate structures involve two main stages:

First, It is anticline structure formation and Second, the further deformation-reformation.

Trap formation timing during second stage is in conformity with reservoir characteristics and hydrodynamic barrier formation. Trapping and Oil accumulation on top of carbonate eroded surface made possible due to equivalence of potential energy (bottom water potential and floating force) with above lateral pressure of infiltration water. Oil, being in contact with circulation water, has been biodegraded. It has high density and high pressures gradient of primary immigration.

More important is hydrodynamic trap on Southern Periclinale (Visoka) of the Patos-Verbas anticline. Tortonian deposits lie with unconformity over carbonate Fig 2. Trapping realised due to these factors: 
-Top carbonate extends with low angle Southward.

-Very high Oil density $(0.998-1.01 \mathrm{gr} / \mathrm{cm} 3)$ and viscosity.

-Carbonate-Molasses contacts consist less permeable.

-Water circulation from outcrop into carbonate.

In conformity to the predominance factors, there created combined traps as follows:

Hydrodynamic-lithologic, hydrodynamic-Stratigraphic merely hydrodynamic, or lithologic-geochemical tectonic block trapping is less spread. It can find only in very complicated geological situation. All the traps related to carbonate reservoirs classified in three groups: massive, combined and tectonic ones.

The first one has structural closure and flysch seal. This type is evidenced encountering carbonate anticlines of Gorishti, Ballshi, Amonica, Seismic line Fig. 3.

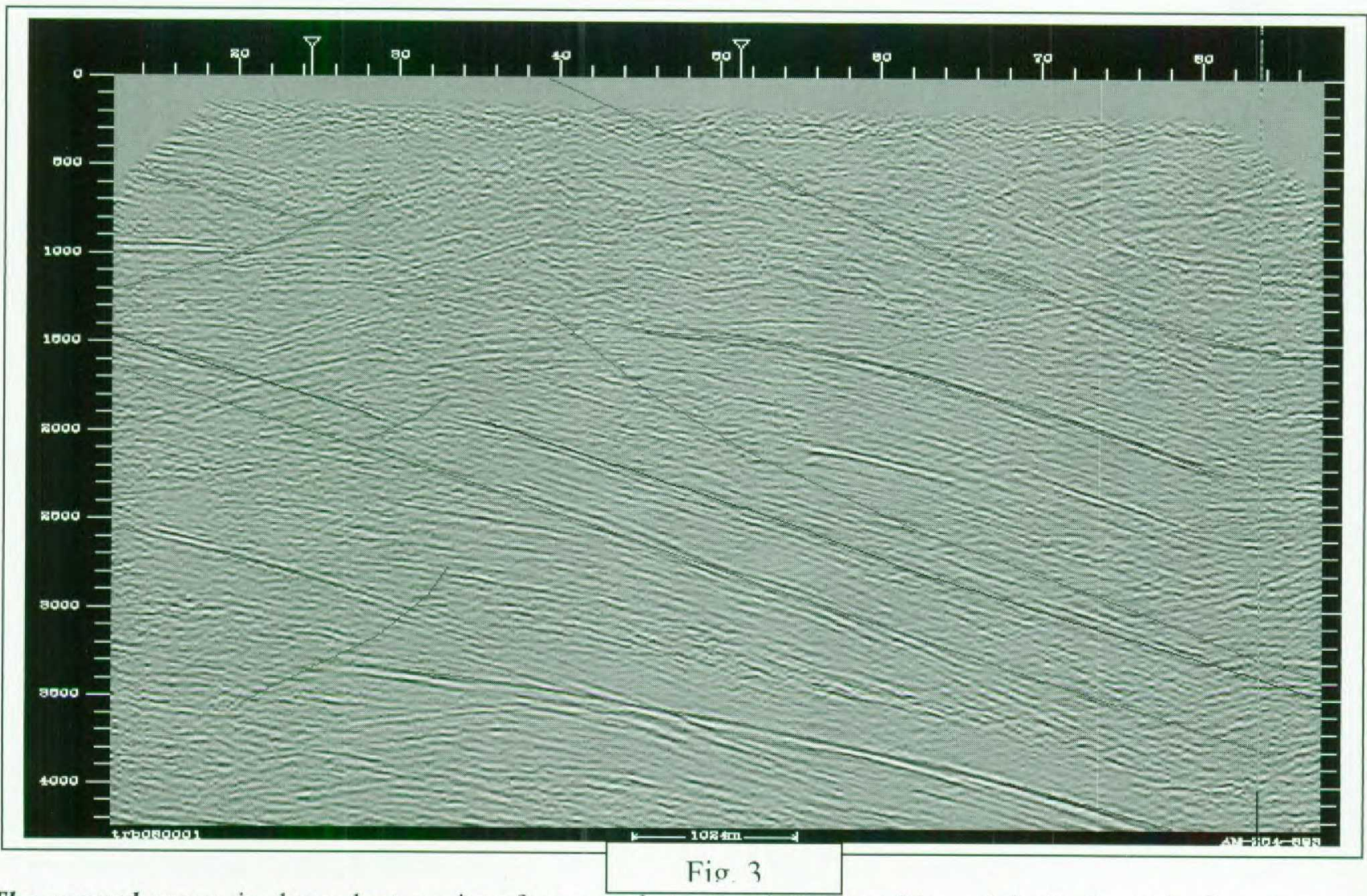

The second group is dependent on interference of structural-stratigraphic and hydrodynamic factors. They are verified on different part of Patos-Verbasi structure. Their characteristic is generally titled oilWater Contact seismic line Fig. 2.

\section{Characteristics of seismic facies belong to orogene carbonates.}

The characteristics of seismic facies for the carbonate section of orogene in the Ionian zone fig. 1,2,3 already are studied.

We have realized internal geometry and external form of seismic facies units, than have combined reflection continuity amplitude and frequency. From our interpretations results the follow characteristics for orogene carbonates: Strong reflections with high amplitude, good continuity with 2-3 phases relatively low frequency about $30 \mathrm{~Hz}$, associated by transparent facies above and under the horizon.

In general, for the Ionian zone the top limestone is associated with two other strong distinguishable reflections that are nearly parallel with top of limestone. These horizons belong to the Cretaceous-Jurassic section. More down these horizons predominate a free and chaotic facies. It is characteristic for dolomite deposits of Triassic and perhaps by the presence of the evaporated section in the Lower part of the carbonate section. 


\section{Characteristics of the seismic facies of the platform carbonates}

The top limestone of the platform as we can see from (Fig. 4) is represented by a strong reflection, high amplitude with good continuity and a low frequency (somewhat lower compared

To the top limestone of the orogene, again horizon from the top limestone is associated with transparent facies only above it. Under this horizon more discontinuous reflections with high amplitude and free

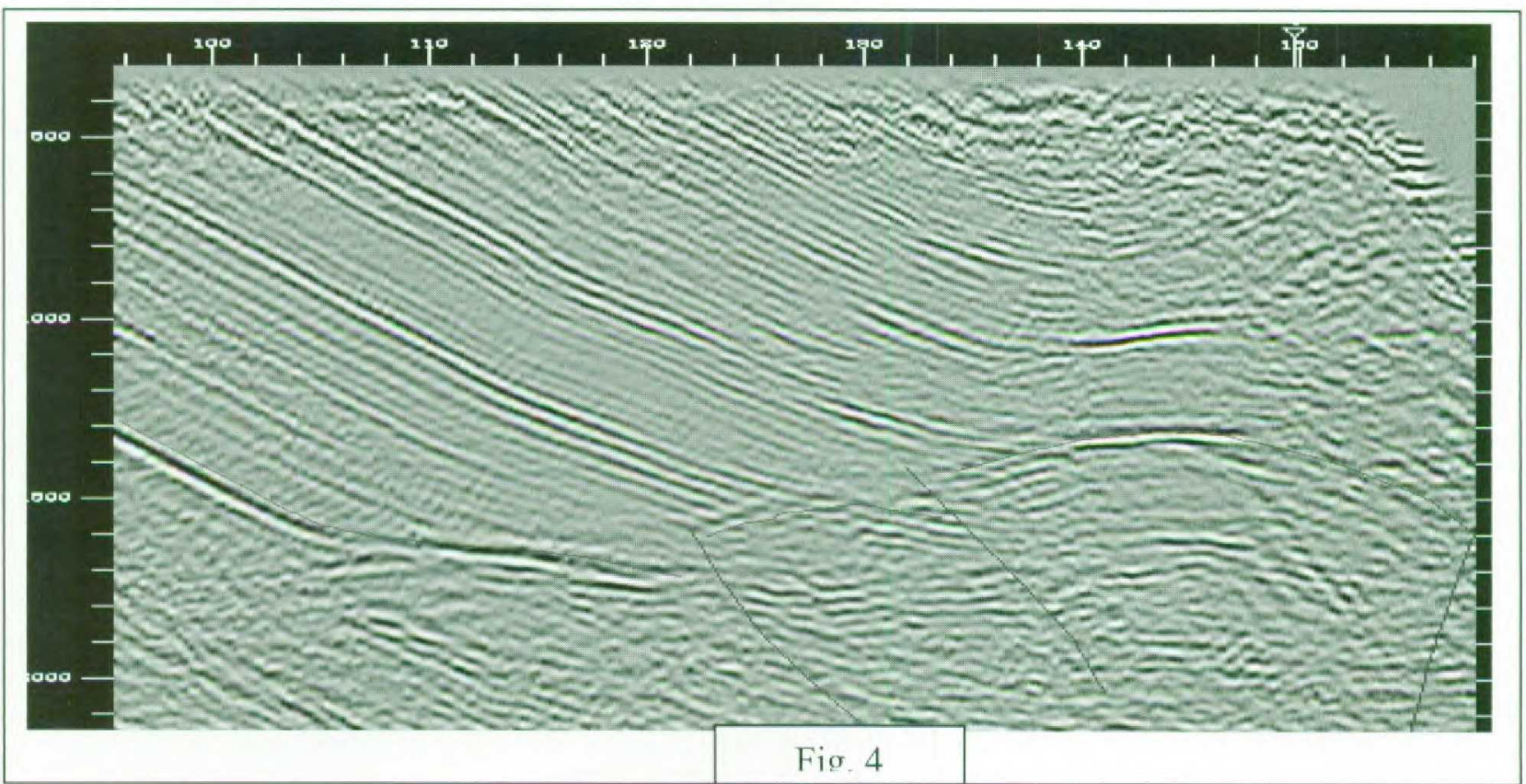

noise, are clearly seen.

Their internal patterns are sigmoid, sigmoid-oblique hummocky and hummocky clinoform.

It is necessary to say differently to the orogene, the other reflection horizons within the carbonate section are not present. This is a distinguishable feature, which is verified in the known zone of the platform in the south part of offshore Albanides.

\section{Conclusions}

In conclusion of the analysis for the geological-geophysical information it can state:

-SeisWork2D is powerful interpretative tool for the traps explorations in carbonate.

-The main factors of the trapping on carbonate reservoirs in Albania are tectonic, lithologo-stratigraphic and hydrodynamic.

-Traps exist not only in classic anticline structures, but they can find and on other complicated situation too.

-Combined traps are formed due to interference of different geological pheromones: as erosion, change of structural plane, transgression, lithological changes, oil biodegradation etc.

-Main stage of the trap formation is Lower Miocene period. During Pliocene-Pleistocene are formed and reformed new traps, according to the predominance of above-mentioned factors.

-Traps tracing in perspective zones of Albania ask detailed analyse of geodynamic and stratigraphic factors.

-Our interpretation is based on facies analyses and consequently have interpret continuity of the platform, as a very important object (target) for exploration 